\title{
PELATIHAN MANAJEMEN PEMASARAN BERBASIS ONLINE DI DUSUN BUKIT PERJUANGAN KABUPATEN LABUHANBATU
}

\author{
ONLINE BASED MARKETING MANAGEMENT TRAINING IN BUKIT \\ PERJUANGAN HAMLET, LABUHANBATU DISTRICT
}

\author{
Bhakti Helvi Rambe ${ }^{1 *}$, Fauziah Hanum ${ }^{2}$, Yudi Prayoga ${ }^{3}$ \\ ${ }^{13}$ (Prodi Akuntansi, Fakultas Ekonomi dan Bisnis, Universitas Labuhanbatu, Indonesia) \\ ${ }_{2}^{2}$ (Prodi Manajemen, Fakultas Ekonomi dan Bisnis, Universitas Labuhanbatu, Indonesia \\ ${ }^{1}$ bhaktihelvirambe@gmail.com; ${ }^{2}$ fauziahhanummrp@gmail.com; ${ }^{3}$ pravogavudi03@gmail.com
}

\begin{abstract}
Abstrak
Pengabdian kepada masyarakat bertempat di Dusun Bukit Perjuangan bertujuan untuk membantu permasalahan yang dihadapi para pelaku UMKM, karena kurangnya kemampuan para pelaku UMKM dalam menguasi IPTEK, berpikir kreatif dan berinovasi dalam memasarkan produk yang akan dijual. Persiapan dilakukan dengan melakukan wawancara untuk melihat kondisi di lapangan mengenai masalah yang dihadapi masyarakat, kemudian kegiatan PKM dilaksanakan dengan dua sesi yaitu sosialisasi peran sosial media bagi para pelaku UMKM dan pelatihan pembuatan akun Facebook, Instagram, Website serta akun berjualan di Maketplace. Hasil menunjukkan bahwa pelaku UMKM di Dusun Bukit Perjuangan sudah mempunyai akun media sosial untuk berjualan dan mampu untuk menggunakannya, serta masyarakat sudah paham trik-trik jitu dalam memasarkan produk secara online serta mampu untuk menciptakan ide-ide baru yang bersumber dari media-media online. Saran kepada aparatur desa agar sering mengadakan sosialisasi maupun pelatihan-pelatihan bagi para masyarakat desa yang baru akan memulai usahanya sehingga membangkitkan keyakinan dan semangat dalam menekuni usahanya.
\end{abstract}

Kata Kunci: Manajemen Pemasaran, Media Sosial, Pelaku UMKM

\begin{abstract}
This community service which is located in Bukit Perjuangan Hamlet aims to help the problems faced by MSME players, due to the lack of ability of MSME players in mastering science and technology, creative thinking, and innovating in marketing the products to be sold. Preparation was carried out by conducting interviews to see conditions in the field regarding problems faced by the community, then PKM activities were carried out in two sessions, namely the socialization of the role of social media for MSME actors and training on creating Facebook, Instagram, Website and selling accounts on Marketplace. The results show that MSME players in Bukit Perjuangan already have social media accounts to sell and are able to use them, and the community already understands the right tricks in marketing products online and is able to create new ideas sourced from online media. Suggestions to village officials to conduct frequent socialization and training for village communities who are just starting their business so as to generate confidence and enthusiasm in pursuing their business.
\end{abstract}

Keyword: Marketing Management, Social Media, UMKM Community.

\section{PENDAHULUAN}

Dunia bisnis semakin berkembang dari waktu ke waktu. Pemasaran yang baik merupakan kunci sukses dari sebuah usaha yang dijalankan baik dibidang manufaktur, 
dagang, maupun jasa. Pemasaran adalah keseluruhan sistem dari berbagai bisnis atau kegiatan bisnis yang bertujuan untuk merencanakan, menentukan harga barang atau jasa, mempromosikannya, mendistribusikannya, dan memuaskan konsumen (Nurmalasari et al., 2020). Manajemen Pemasaran adalah kegiatan menganalisis, merencanakan, melaksanakan, dan mengendalikan program-program yang disusun dalam pembentukan, pembangunan, dan pemeliharaan keuntungan dari pertukaran/ transaksi melalui sasaran pasar dengan harapan untuk mencapai tujuan dalam jangka panjang (Widodo et al., 2019).

Di era modernisasi seperti sekarang ini, pemasaran tidak hanya dapat dilakukan dengan cara tradisional dengan langsung bertatap muka dengan pembeli di lapangan, maka harus mulai mencoba menggunakan pemasaran modern yang berbasis online.

Media Sosial kini telah menjadi trend dalam komunikasi pemasaran, semua kalangan menggunakan media sosial untuk berkomunikasi antara pengusaha maupun tokoh masyarakat dengan para pengguna sosial media yang lain. Contoh-contoh sosial media yang mengalami perkembangan saat ini adalah: Twitter, Facebook, Youtube, instagram, Whatsapp, Website, Platform Marketplace dll. Menurut Masitoh, (2019), manfaat digital marketing bagi perusahaan dalam kegiatan pemasaran produk ataupun jasa adalah sebagai berikut: 1). Kecepatan Penyebaran, Strategi pemasaran dengan menggunakan media digital bisa dilakukan dengan sangat cepat, bahkan dalam hitungan detik. Selain itu, pemasaran digital dapat diukur dengan real-time dan tepat. 2). Kemudahan Evaluasi. Dengan berbagai aplikasi di media online, hasil dari kegiatan pemasaran dapat dengan mudah diketahui mengenai informasi berapa persentase keuntungan penjualan. 3). Jangkauan Lebih Luas. Jangkauan geografis dari digital marketing yang luas dapat memasarkan produk hingga ke pelosok nusantara dan mancanegara hanya dengan beberapa langkah mudah dengan memanfaatkan fasilitas sosial media.

Menurut Turmudi et al., (2019) pemasaran digital adalah pemasaran dengan menggunakan aplikasi teknologi secara digital. Salah satu bentuk pemasaran digital dengan menggunakan media elektronik atau internet adalah pemasaran internet (e-marketing). Pendapat dari (Mujianto et al., 2020), Online Marketing adalah kegiatan promosi dan mencari pasar melalui media digital online dengan menggunakan berbagai sarana seperti jejaring sosial, sedangkan Chaffey dan Ellis-Chadwick, (2019) menyebutkan digital 
marketing adalah kegiatan marketing termasuk branding yang menggunakan berbagai media berbasis web seperti blog, website, e-mail, ataupun jejaring sosial.

Berdasarkan data dari Badan Pusat Statistik (BPS) Indonesia total Usaha Mikro Kecil dan Menengah (UMKM) menembus 64 juta. Kontribusi UMKM terhadap PDB pada tahun 2018 mencapai 60,34 Persen dan hanya 13 persen atau 8 juta UMKM dari 64 Juta yang hadir dalam platform digital (Irvi dan Husna, 2020).

Meskipun kontribusi UMKM terhadap PDB cukup signifikan terhadap pertumbuhan ekonomi, namun nasih banyak UMKM mengalami kesulitan dalam pemasaran produknya. Hal ini tidak terlepas dari pengetahuan dan kemampuan melakukan inovasi dalam pemasaran produk. Dewasa ini pemasaran digital menjadi salah satu inovasi pemasaran untuk meningkatkan daya saing usaha. Perkembangan IPTEK seperti sekarang ini, pemasaran tidak hanya dapat dilakukan dengan cara konvensional dengan hanya bertatap muka dengan pembeli di lapangan/ Pasar, maka kita harus mulai mencoba menggunakan pemasaran modern yang berbasis online. Oleh karena itu kegiatan pelatihan manajemen pemasaran berbasis online ini menjadi penting dilaksanakan. Tujuan pelaksanaan pengabdian masyarakat antara lain membina hubungan baik dengan masyarakat yang dibina dengan mengenal wilayah, tokoh-tokoh masyarakat dan potensi ekonomi di wilayah tersebut serta masyarakat dusun dapat meningkatkan kemampuannya dalam menggunakan media berbasis online dalam memasarkan produk nya.

\section{METODOLOGI}

\section{Bentuk Kegiatan}

Adapun bentuk kegiatan yang dilakukan dalam pengabdian masyarakat ini adalah sosilasisasi dan pelatihan kepada para pelaku UMKM yang ada di dusun bukit perjuangan untuk membuat akun khusus untuk berjualan seperti facebook, Instagram, akun di Marketplace dan Website. Berikut ini adalah beberapa permasalahan yang di alami masyarakat dusun bukit perjuangan yang dituangkan dalam Tabel 1 .

\section{Teknis Pelaksanaan}

Persiapan dimulai dengan melakukan survei ke lokasi desa bukit perjuangan dan melakukan interview dengan para pelaku UMKM, Juni 2020 mengurus surat ke LPPM Universitas Labuhanbatu untuk melaksanakan kegiatan pengabdian masyarakat, selanjutnya 
tanggal 10 Agustus 2020 tim pelaksana mengurus persuratan ke kantor kepala desa kampung baru, Labuhanbatu. Program in selanjutnya disampaikan kepada Kepala Dusun untuk berkoordinasi dengan warga.

\section{Pelaksanaan Kegiatan}

Kegiatan pengabdian masyarakat ini dilaksanakan mulai pukul 09.00-12.30 siang, dilaksanakan dalam dua termin. Pada jam 09.00-10.00 adalah Sosialasi mengenai peran sosial media bagi para pelaku UMKM yang di ikuti oleh 40 orang peserta dan dihadiri oleh perwakilan Aparatur Desa dan Kepala Dusun. Pembahasannya meliputi trik-trik jitu dalam pemasaran online dan keuntungan dalam pemasaran online. Kemudian pada jam 10.00-12.30 dilakukan pelatihan membuat akun facebook, Instagram, Akun di Marketplace dan membuat website untuk para pelaku UMKM dan peserta diajarkan bagaimana menggunakan Akun media sosial tersebut.

\section{Tabel 1. Pemasalahan Mitra}

\begin{tabular}{|c|c|}
\hline kat Desa & Solusi Dari Permasalahan Mitra \\
\hline $\begin{array}{l}\text { Permasalahan yang dialami para pelaku } \\
\text { UMKM dalam menguasi IPTEK, tidak } \\
\text { memiliki akun media sosial dan tidak paham } \\
\text { cara menjalankan nya. }\end{array}$ & $\begin{array}{l}\text { Sosialisasi dan pelatihan pembuatan akun di } \\
\text { sosial media agar tidak hanya mampu } \\
\text { memasarkan barang secara konvensional. }\end{array}$ \\
\hline $\begin{array}{l}\text { Permasalahan keuangan bagi para pelaku } \\
\text { UMKM yaitu keterbatasan modal untuk } \\
\text { memulai atau mengembangkan produk- } \\
\text { produknya }\end{array}$ & $\begin{array}{l}\text { Sosialisasi cara-cara untuk mendapatkan ide- } \\
\text { ide kreatif yang bersumber dari media sosial } \\
\text { dan yang tidak memerlukan modal yang } \\
\text { besar. }\end{array}$ \\
\hline $\begin{array}{l}\text { Masyarakat desa yang kurang kreatif, dan } \\
\text { tidak mampu untuk berinovasi serta bersaing } \\
\text { dengan produk-produk yang lain }\end{array}$ & $\begin{array}{l}\text { engajarı trik-trik jitu agar mampu untuk } \\
\text { eningkatkan inovasi dan kreatifitas melalui } \\
\text { edia online. }\end{array}$ \\
\hline
\end{tabular}

\section{PEMBAHASAN}

Masyarakat Dusun Bukit Perjuangan sangat antusias dalam mengikuti sosialisasi dan pelatihan tersebut. Beberapa orang mengajukan pertanyaan kepada narasumber terkait dengan cara-cara pemasaran online yang kreatif serta terkait dengan ketidakmampuan para peserta dalam menggunakan sosial media. 
Pelaksanaan Pengabdian kepada Masyarakat di dusun bukit perjuangan berjalan dengan sukses dan mendapat sambutan yang luar biasa dari warga dusun. Jumlah Warga adalah 80 KK (Kartu Keluarga) yang ada di dusun tersebut dan 50\% dari mereka hadir pada acara sosialisasi dan pelatihan manajemen pemasaran berbasis online. Acara dibagi menjadi dua termin, Pertama pada jam 09.00-10.00 pagi bertempat di rumah bapak kepala dusun. Acara tersebut dihadari oleh perwakilan dari aparatur desa, kepala dusun dan dibantu oleh adik-adik mahasiswa Universitas Labuhanbatu Tahun 2020. Pada saat sosialisasi dibahas mengenai peran sosial media bagi para pelaku UMKM. Narasumber menjelaskan mengenai manfaat, kelebihan dan kekurangan dari penggunaan media sosial untuk sarana mempromosikan produk.

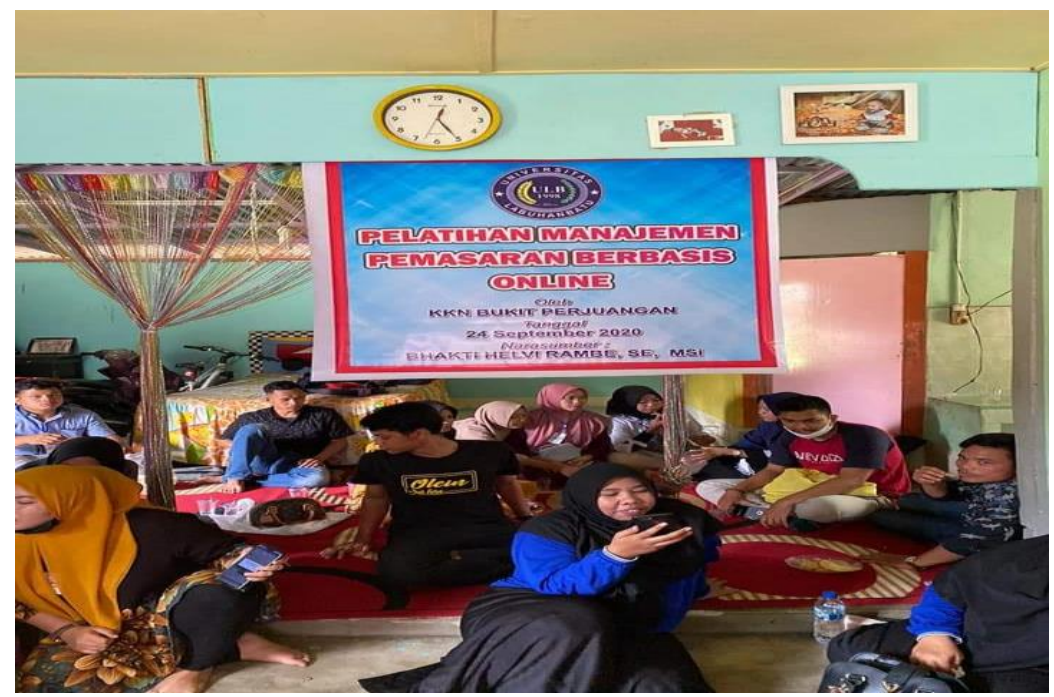

Figur 1. Sosialisasi Kegiatan Kepada Pengabdian Masyarakat di Desa Bukit Perjuangan

Selanjutnya diberikan beberapa trik-trik jitu ketika mempromosikan dagangan di sosial media. Antusias warga sangat besar karena 90\% dari warga tidak paham mengenai sosial media dan belum mempunyai akun sosial media, padahal di dusun tersebut mayoritas dari warga adalah pelaku usaha rumahan seperti donat, kue kering, kerupuk, keripik dll yang hanya memasok dagangannya ke warung-warung terdekat saja. Pertanyaan pun banyak muncul dari warga mengenai ketertarikan mereka mengenai pemasaran secara online. Narasumber juga memberikan arahan kepada para warga yang tertarik untuk berjualan tapi tidak mempunyai modal agar tidak lagi merasa takut dan tidak percaya diri untuk memulai usaha, karena dengan memasarkan produk secara online kita bisa menggunakan modal yang sedikit. 

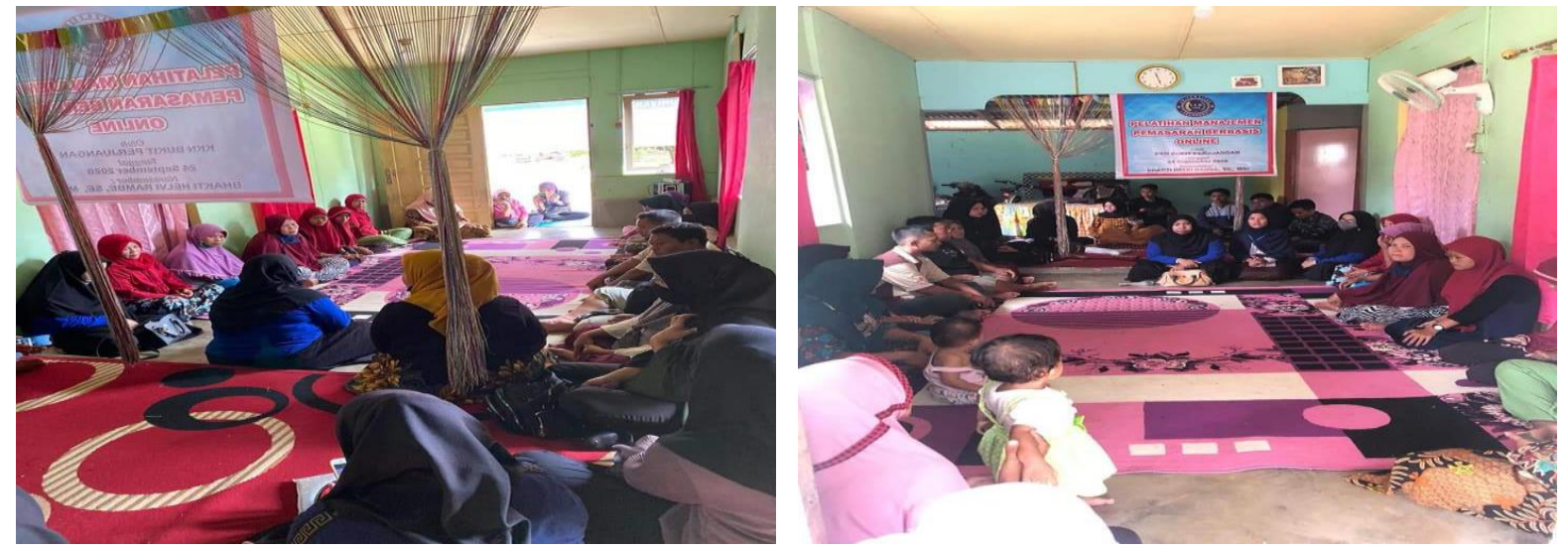

Figur 2. Persentasi dengan Materi Meningkatan Omset dalam Berjualan Online

Selanjutnya pada termin kedua dilakukan pelatihan pembuatan dan penggunaan akun media sosial yang dimulai pada pukul 10.00-12.30. Jumlah warga yang hadir sebanyak 40 orang, tetapi yang membawa Hp hanya 30 orang. Mahasiswa ikut memandu para warga dalam mendaftarkan akun Facebook, Instagram, Website, dan Akun di Marketplace.

Diatara 30 peserta yang mengkuti cara-cara pembuatan akun Facebook dan cara penggunaannya tersebut sebanyak 15 orang masih kurang paham mengenai cara mengoperasikan facebook. Hampir sama dengan pembuatan akun media sosial yang lain seperti Instagram, Website dan Akun marketplace hanya sebagian diantara mereka yang langsung bisa menggunakan aplikasi tersebut. Tim pengabdian terus semangat untuk mengajari para warga agar mengerti tentang cara menggunakan akun tersebut. Sampai akhir acara warga masih antusias untuk belajar cara menggunakan sosial media sebagai wadah untuk mempromosikan produk-produk mereka. Dokumentasi pelaksanaan kegiatan pengabdian masyarakat di dusun Bukit Perjuangan Kabupaten Labuhanbatu.

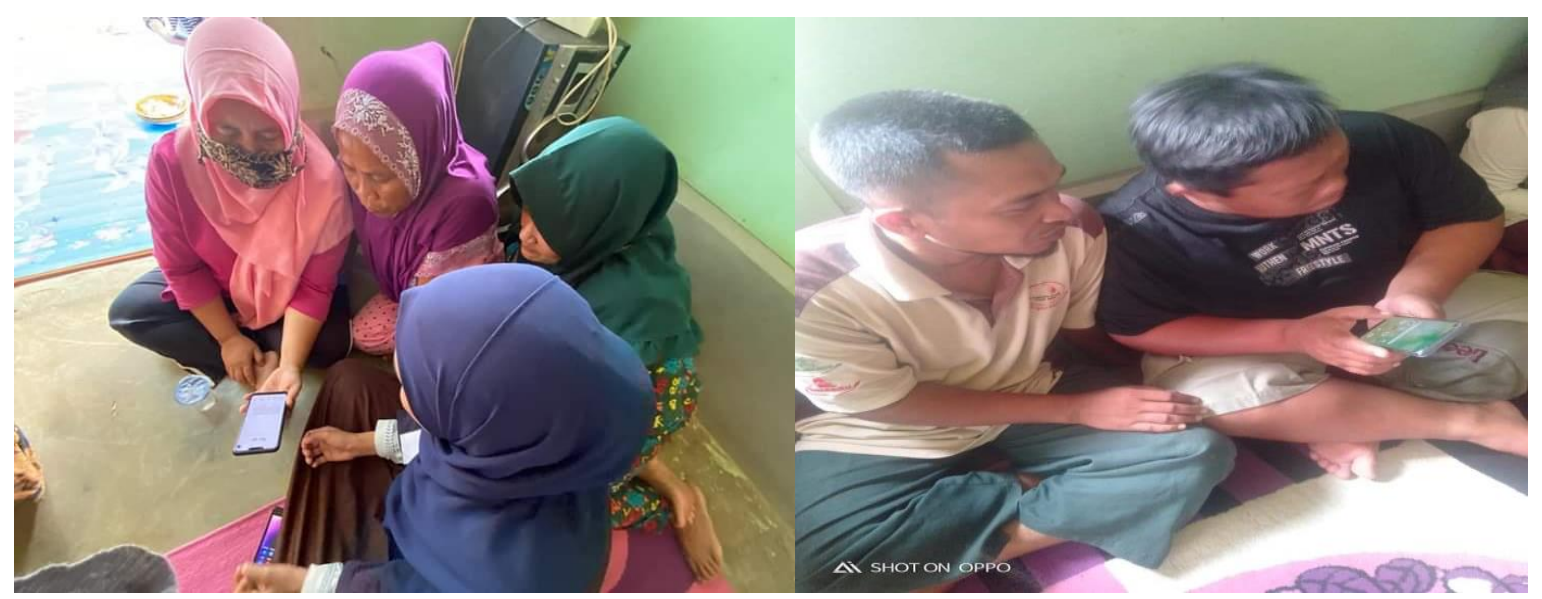

Figur 3. Pembuatan dan Pengunaan Media Sosial untuk Penjualan Produk 


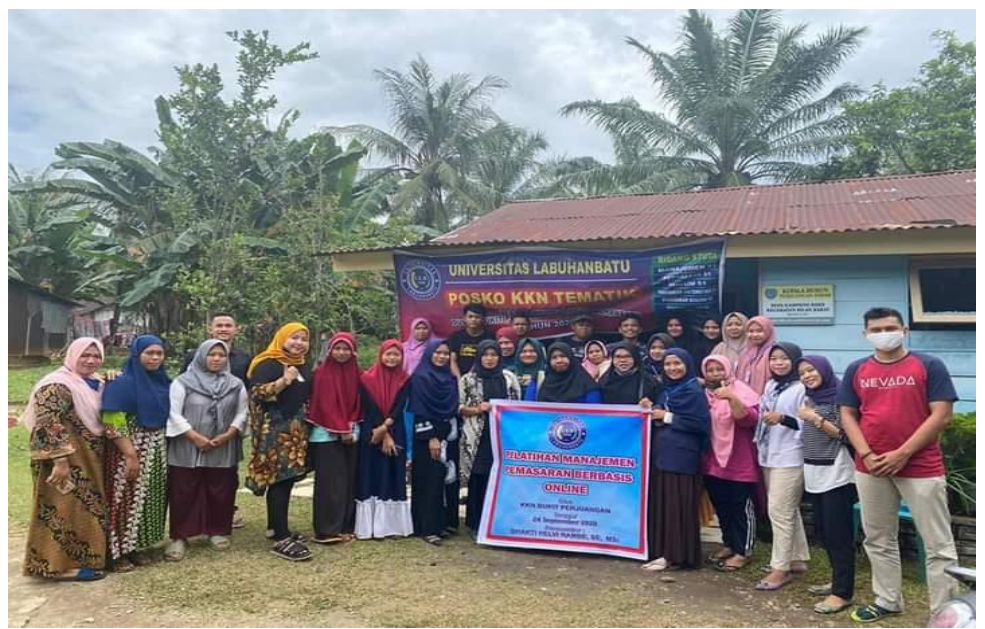

Figur 4. Foto Bersama setelah selesai Kegiatan

\section{KESIMPULAN DAN SARAN}

Hasil yang diperoleh dalam kegiatan pengabdian ini antara lain para pelaku UMKM di dusun bukit perjuangan memiliki akun khusus untuk berjualan di marketplace, akun facebook, Instagram maupun website untuk memudahkan pemasaran secara online, selanjutnya di dapatkan hasil dari sosialisasi bahwa masyarakat sudah mampu untuk mencontohkan ide-ide kreatif baru yang bersumber dari media sosial, serta masyarakat yang mau memulai usaha agar tidak takut karena dengan bantuan pemasaran melalui media online kita tidak membutuhkan modal yang besar untuk memulai usaha.

Saran yang diajukan dalam kegiatan pengabdian masyarakat ini . Aparatur desa dibantu kepala dusun membentuk komunitas bagi para pelaku UMKM di dusun tersebut sebagai wadah saling bertukar pikiran dalam mengembangkan usaha serta menciptkan ide-ide yang menarik, kreatif dan kekinian. Aparatur desa harus sering mengadakan sosialisasi maupun pelatihan-pelatihan bagi para masyarakat desa yang akan memulai usahanya sehingga membangkitkan keyakinan dan semangat dalam menekuni usahanya.

\section{UCAPAN TERIMA KASIH}

Tim Pelaksana menghaturkan ucapan terima kasih kepada semua pihak yang telah berpartisi ats terlaksananya kegiatan Pengabdian Masyarakat ini, terutama kepada: Rektor Universitas Labuhanbatu, Ketua LPPM Universitas Labuhanbatu, Dekan Fakultas Ekonomi dan bisnis Universitas Labuhanbatu, Ketua Program Studi Akuntansi Universitas 
Labuhanbatu, Bapak Kepala Desa Kampung Baru Kab. Labuhanbatu atas kerjasama yang terbangun selama kegiatan pengabdian masyarakat, Bapak Kadus Bukit Perjuangan yang membantu penyelenggaraan aacara sampai selesai, Warga Dusun Bukit Perjuangan atas kerjasama dan antusiasnya dalam kegiatan ini, Adik-adik mahasiswa yang banyak membantu proses persiapan dan pelaksanaan sehingga kegiatan pengabdian menjadi lebih maksimal.

\section{REFERENSI}

Chaffey, D., dan Ellis-Chadwick, F. (2019). Digital marketing. https://books.google.co.id/ books?hl=id\&lr=\&id=-1 yGDwAAQBAJ

Irvi, A., dan Husna, N. (2020). Kebijakan Peningkatan Usaha Mikro, Kecil, dan Menengah di. Muttaqien;Indonesian Journal of Multiciplinary Islamic Studies, 1(1), 45-58.

Kumala, M.C. dan Widodo. (2019). Pengaruh Harga Dan Kualitas Produk Terhadap Loyalitas Pelanggan Alumunium. Jurnal Manajemen Bisnis Krisnadwipayana, 7(2), $57-66$.

Masitoh, A. (2019). The Importance of Archive Management Systems in Digital Era. https://books.google.co.id/books?id=ZvLGDwAAQBAJ

Mujianto, A. H., Sucipto, H., Mashuri, C., Permadi, G. S., dan Vitadiar, T. Z. (2020). Implementasi Online Market Place Pada Industri Rumahan Di Desa Mojodanu Ngusikan Jombang. Abidumasy: Jurnal Pengabdian Kepada Masyarakat, 1(1), 13-23.

Nurmalasari, N., dan Masitoh, I. (2020). Manajemen Strategik Pemasaran Pendidikan Berbasis Media Sosial. Journal of Management Review, 4(3), 543-548. https://doi.org/10.25157/mr.v4i3.4524

Turmudi, H., Widiati, I. S., dan Purwidiantoro, M.H. (2019). Pelatihan Pemuda Desa di Boyolali Dalam Pemasaran Digital Produk Olahan Minyak Jelantah.. Seminar Nasional Pengabdian Pada Masyarakat (SNPMas), hlm 334-343. STMIK Dipanegara Makassar, 16 Desember 2019 